\title{
An Event-Related Potential Investigation of Response Inhibition in Schizophrenia and Psychopathy
}

\author{
Kent A. Kiehl, Andra M. Smith, Robert D. Hare, and Peter F. Liddle
}

Background: Schizophrenia and psychopathy are both characterized by impulsive, poorly planned behavior. This behavior may originate from a weak or poorly coordinated response inhibition system. We tested the hypothesis that schizophrenia and psychopathy are associated with abnormal neural processing during the suppression of inappropriate responses.

Methods: The participants were schizophrenic patients, nonpsychotic psychopaths, and nonpsychotic, nonpsychopathic control subjects (defined by the Hare Psychopathy Checklist-Revised), all incarcerated in a maximum security psychiatric facility. We recorded behavioral responses and event-related potentials (ERPs) during a Go/No Go task.

Results: Schizophrenic patients made more errors of commission than did the nonpsychopathic offenders. As expected, the nonpsychopathic nonpsychotic participants showed greater frontal ERP negativity (N275) to the No Go stimuli than to the Go stimuli. This effect was small in the schizophrenic patients and absent in the psychopaths. For the nonpsychopaths, the P375 ERP component was larger on Go than on No Go trials, a difference that was absent in schizophrenic patients and in the opposite direction in psychopaths.

Conclusions: These findings support the hypothesis that the neural processes involved in response inhibition are abnormal in both schizophrenia and psychopathy; however, the nature of these processes appears to be different in the two disorders. Biol Psychiatry 2000;48:210-221 (C) 2000 Society of Biological Psychiatry

Key Words: Schizophrenia, psychopathy, response inhibition, Go/No Go paradigm, response suppression, eventrelated potentials

\section{Introduction}

Chizophrenia and psychopathy are complex conditions with heterogeneous clinical presentation. Although these conditions differ in many respects, impulsive, poorly planned behavior is characteristic of both schizophrenia (Bleuler 1950; Kraepelin 1919) and psychopathy (Cleckley 1976; Hare 1993). In addition, recent research suggests that psychopaths exhibit subtle disorders resembling the disorganization of thought and behavior that occur in schizophrenia (Gillstrom 1995; Hare 1993; Williamson 1991).

The purpose of the present study was to examine the neural correlates of behavioral inhibition in psychopaths and nonpsychopaths, and chronic, medicated schizophrenic patients, all incarcerated in a maximum security forensic facility. We recorded behavioral responses and event-related potentials (ERPs) while the participants performed a Go/No Go task. The ERP Go/No Go paradigm allowed us to examine the neural processes involved with making, and inhibiting, behavioral responses. We hypothesized that the schizophrenic patients and psychopaths would show anomalies in the neural processes involved in behavioral inhibition. Comparison of the spatial and temporal characteristics of the ERPs generated during the Go/No Go task offers the possibility of establishing similarities and differences in the neural processes associated with response generation and inhibition in the two disorders. In general, such a strategy can help to distinguish abnormalities that are specific to a disorder from abnormalities that are a nonspecific correlate of the functional impairment that occurs in the disorder.

\section{The Disorganization Syndrome in Schizophrenia}

Many studies indicate that the characteristic symptoms of schizophrenia segregate into three groups: psychomotor poverty, disorganization, and reality distortion (Andreasen et al 1995; Bilder et al 1985; Liddle 1987b; Malla et al 1993). Psychomotor poverty includes the core negative symptoms of poverty of speech, blunted affect, and reduced spontaneous movement (Liddle 1987a; Malla et al 1993). Disorganization includes formal thought disorder, bizarre behavior, and

\footnotetext{
From the Departments of Psychology (KAK, AMS, RDH) and Psychiatry (PFL), University of British Columbia, Vancouver, Canada.

Address reprint requests to Kent A. Kiehl or Robert D. Hare, University of British Columbia, Department of Psychiatry, 2255 Wesbrook Mall, Vancouver, B.C., Canada V6T 2A1.

Received June 16, 1999; revised January 10, 2000; accepted January 19, 2000.
} 
inappropriate affect. Reality distortion includes delusions and hallucinations.

On the basis of the similarities between the clinical features of these three syndromes and the clinical features associated with focal brain lesions, Liddle (1987a) proposed that each of the three syndromes was associated with a specific pattern of disordered regional brain function. In particular, the disorganization syndrome resembles the pseudopsychopathic syndrome that arises from damage to the ventral prefrontal cortex (Blumer and Benson 1975; Damasio et al 1990). The pseudopsychopathic syndrome is characterized by impulsive behavior, rambling speech, and fatuous affect. In view of the fact that both the disorganization syndrome in schizophrenia and the pseudopsychopathic syndrome entail dysregulation of behavior, thought, or speech and affect, Liddle (1987a) proposed that both might arise from disordered function of right ventral frontal and medial prefrontal regions involved in the inhibition of inappropriate mental activity.

In support of this hypothesis, Liddle and Morris (1991) demonstrated that severity of disorganization, but not reality distortion or psychomotor poverty, is correlated with impaired performance in tasks that involve the selection of an appropriate response, such as the Stroop Color-Word Test and the Reitan Trails B Test. Other investigators have confirmed the association between formal thought disorder and impaired Stroop performance (Baxter and Liddle 1998). Frith et al (1991) demonstrated that formal thought disorder and incongruity of affect, the cardinal features of the disorganization syndrome, were associated with errors of commission during a continuous performance test.

To test the hypothesis that the disorganization syndrome is associated with aberrant activity in ventral and medial prefrontal cortex, Liddle et al (1992) used positron emission tomography (PET) to determine the pattern of correlation between regional cerebral blood flow ( $\mathrm{rCBF}$ ) and severity of the disorganization syndrome. In accordance with prediction, they found that the disorganization syndrome was correlated with underactivity in right ventral prefrontal cortex and contiguous insula, and with overactivity in right anterior cingulate. The site of overactivity in anterior cingulate cortex coincided with the site demonstrated to be maximally activated in healthy participants during the performance of the Stroop Test (Pardo et al 1990). In the Stroop Test, the participant is required to inhibit a tendency to respond to irrelevant aspects of a stimulus. The observation that disorganization is associated with overactivity in anterior cingulate is consistent with the proposal that, in patients with disorganization syndrome, inadequate activation of ventral prefrontal function results in the intrusion of inappropriate mental activity into current mental processing, leading to abnor- mal overactivity in the anterior cingulate region involved in suppressing inappropriate responses.

Subsequent studies of rCBF have provided partial confirmation of these findings, though there have been some discrepancies. For example, Ebmeier et al (1993), and Yuasa et al (1995) both confirmed that disorganization is associated with overactivity in anterior cingulate, though neither of these studies found an association with underactivity in the ventral frontal cortex.

Overall, the observed similarity between the pseudopsychopathic syndrome and the disorganization syndrome has proved to be a source of fruitful hypotheses regarding the nature of the cerebral abnormalities associated with the disorganization syndrome. The utility of the similarities between the two syndromes for generating further hypotheses about the underlying neural mechanisms is limited, however, by the fact that pseudopsychopathy arises from gross lesions to the brain (Blumer and Benson 1975; Damasio et al 1990), whereas schizophrenia is not usually associated with gross structural lesions (Raz and Raz 1990). In contrast, psychopathy, which involves abnormalities of response inhibition similar in some respects to those occurring in pseudopsychopathy (Cleckley 1976; Hare 1993), does not arise from a gross structural lesion of the brain, and hence is potentially a more appropriate condition to compare with schizophrenia.

\section{Psychopathy and Response Selection}

Psychopathy is a personality disorder defined by a constellation of affective, interpersonal, and behavioral characteristics, including egocentricity, lack of empathy or guilt, shallow affect, impulsivity, sensation-seeking, poor behavioral controls, and a persistent violation of social norms and expectations. Psychopaths are more likely than normal individuals to act on the spur of the moment, without considering the possible consequences of their actions (Cleckley 1976; Hare 1993).

Newman (1998) has argued that much of the impulsive, disinhibitory behavior of psychopaths, including difficulty in avoiding punishment and inhibiting dominant response sets, is the result of poor response modulation, defined as a cognitive processing deficit that hampers the ability to accommodate the meaning of contextual cues while engaged in the active organization and implementation of goal-directed behavior. Newman (1998) proposes that the poor response modulation of psychopaths represents a situation-specific failure to suspend ongoing behavior and to reallocate attentional resources.

Laboratory studies of response inhibition in psychopaths have produced mixed results. For example, Newman and his colleagues (Newman and Kosson 1986; Newman et al 1985; Newman et al 1990; Patterson and Newman 
1993) consistently have found that psychopaths are relatively poor at learning to inhibit reward-seeking behavior that results in monetary punishment. Lapierre et al (1995) reported that psychopaths made significantly more errors of commission when performing a Go/No Go task than did nonpsychopaths; however, this latter task also placed substantial demands on visuo-spatial processing, making interpretation of this finding difficult. Raine (1985) found that psychopaths did not make more errors of commission than did nonpsychopaths during performance of a continuous performance task.

Inconsistent results also have been obtained from studies of the performance of psychopaths on other tasks that require inhibition of dominant response sets and shifts in the allocation of attentional resources, including the Wisconsin Card Sorting Test (WCST), the Stroop Test, and the Trails B Test. Newman and Wallace (1993) reported that psychopaths performed more poorly than did nonpsychopaths on the Trails B Test. Similar results were obtained by Hart et al (1990) in one sample of offenders, but the results were not replicated in a larger sample of offenders. In addition, there is little evidence that psychopaths consistently perform poorly on the WCST or the Stroop Test (Gorenstein 1982; Hare 1984).

In general, it appears that impaired response inhibition in laboratory tasks is not nearly as pronounced in psychopaths as it is in schizophrenic patients. It is worth noting that in schizophrenic patients impairment on response inhibition tasks is associated with formal thought disorder and incongruity of affect (Frith et al 1991; Liddle and Morris 1991), both key elements of the disorganization syndrome (Liddle 1987a). Interestingly, there is some evidence that psychopathy also may be associated with thought disorder (Cleckley 1976; Gillstrom 1995; Hare 1993; Williamson 1991). Although thought disorder in psychopathy is more subtle than that observed in schizophrenia, thorough investigation of psychopaths' speech and language reveals substantial abnormalities, including derailment, tangentiality and a lack of coherence (Williamson 1991). Williamson (1991) also found that 20 of 21 psychopaths, assessed with the Psychopathy Checklist-Revised (PCL-R; Hare 1991), met the Thought, Language and Communication (TLC; Andreasen 1979) criteria for thought disorder. B.J. Gillstrom (unpublished data, 1994) found that psychopaths performed poorly the Proverbs test, a test that reflects a breakdown in thought processes and is sensitive to the thought disorder associated with schizophrenia (Gorham 1956). Recently, we have shown that the visual P3 elicited by target stimuli is reduced in psychopaths compared to nonpsychopaths (Kiehl et al 1999b). One interpretation of these P3 effects in psychopaths is that it reflects subtle thought disorder (Ward et al 1992). Thus, there is accumulating evidence that psychopathy is associated with subtle thought disorder.
Of course, psychopathy and schizophrenia also differ in many respects. For example, lack of conscience and an ability to manipulate and control others are features of psychopathy but not of schizophrenia, while many features of schizophrenia, including delusions, hallucinations, and the core negative symptoms (poverty of speech and decreased voluntary activity) are not characteristic of psychopathy. Nonetheless, the possibility that the disorganization syndrome found in schizophrenics may also occur in psychopaths, though to a less pronounced and dramatic degree, implies that similar neurologic mechanisms may underlie some features of the two disorders. In the present study, we investigated neural mechanisms associated with response selection in a Go/No Go paradigm. Our goal was to distinguish those neural abnormalities that are specific to each of the two disorders from those that reflect a nonspecific neural disorder of response selection.

\section{Go/No Go Paradigm}

Go/No Go paradigms have been used in both animal and human experimentation to assess impulsivity, learning, and response to reward and punishment (Brown et al 1989; Schroger 1993; Watanabe 1986). The neural correlates of several different Go/No Go tasks have been studied with ERPs. The most common ERP components to show modulation during a visually presented Go/No Go task include a negative potential with a fronto-central distribution at approximately 275 msec poststimulus (N2) and a centro-parietal positive potential at $300 \mathrm{msec}(\mathrm{P} 3)$. The anterior N2 is larger for No Go trials than for Go trials, and has been interpreted as a reflection of early response inhibition processes (Eimer 1993; Gemba and Sasaki 1989; Jodo and Kayam 1992; Kok 1986; Naito and Matsumura 1994; Pfefferbaum et al 1985; Simson et al 1977). The posterior P3 is larger for Go trials than for No Go trials and the scalp topography of the P3 has parietal maximum for Go trials and a centro-parietal distribution for the No Go trials. (Hillyard et al 1976; Jodo and Inoue 1990; Karlin et al 1969; Kok 1986; Pfefferbaum and Ford 1988; Pfefferbaum et al 1985; Simson et al 1977). These morphological and topographical P3 differences between Go and No Go trials are thought to reflect late (e.g., $300 \mathrm{msec}$ or later) decision-making processes. We expected that schizophrenic patients and psychopaths would show reduced amplitude of the early No Go N2 "response inhibition" potential. Furthemore, in light of the evidence that the P3 component is abnormal during the classical oddball task in both schizophrenic patients (McCarley et al 1993) and in psychopaths (Kiehl et al 1999a), we further expected that the morphology and topography of the P3 "decision-making" potential 
would be abnormal in both schizophrenic patients and psychopaths. Specifically, we predicted that the posterior P3 to target stimuli would be reduced in psychopaths and in schizophrenic patients relative to the nonpsychopathic control subjects.

\section{Methods and Materials}

\section{Participants}

The participants were 12 schizophrenic patients and 24 nonpsychotic offenders, all male inmates of a federal maximum security psychiatric facility near Vancouver, British Columbia. The offenders were participants in a violent offender or a sex offender treatment program. The schizophrenic patients were either serving life sentences at the institution or were participants in treatment programs. All participants received complete psychiatric assessments as part of their correctional treatment regime. This assessment included administration of the Structured Clinical Interview (SCID). Volunteers were selected for the study if they were between 18 and 55 years of age, had normal, or corrected-to-normal vision, and were right handed (Annett 1970). All psychopathic and nonpsychopathic participants were free from any Axis I disorder. Schizophrenia was assessed by two psychiatrists according to the criteria in the DSM-IV (American Psychiatric Association 1994). The schizophrenic patients were all in a stable period of their illness (no changes in medication or psychotic episodes in the last 60 days), and almost asymptomatic. All of the schizophrenic patients were receiving atypical neuroleptics. None of the other participants were on psychotropic medication.

Two clinicians used a semistructured interview and institutional files to complete the PCL-R (Hare 1991) for each participant. The PCL-R is a reliable and valid instrument for the assessment of psychopathy in criminal and forensic psychiatric populations (Hare 1991; see review by Fulero 1996). Each of the 20 items on the PCL-R is scored on a 3-point scale (0-2) according to the extent to which it applies to the inmate.

The PCL-R was used to divide the offenders into a psychopathic $(n=13)$ and a nonpsychopathic $(n=11)$ group. The cutoff score for assignment to the psychopathic group was 30 or above according to the diagnostic criteria in the PCL-R manual (Hare 1991). The mean PCL-R score was 33.5 ( $\mathrm{SD}=2.2$ ) for psychopaths and $17.9(\mathrm{SD}=6.8)$ for nonpsychopaths. The $\kappa$ coefficient for two independent raters for classification into psychopathic and nonpsychopathic was 1.00. The mean PCL-R score for the schizophrenic patients was $23.5(\mathrm{SD}=4.5)$. None of the schizophrenic offenders satisfied the criterion for psychopathy. The items on the PCL-R segregate into two separate, yet correlated, factors (Harpur et al 1989). Factor 1 assessed the interpersonal characteristics of the psychopath; Factor 2 assessed the behavioral characteristics of the psychopath, including impulsivity. In the present study, Factor 1 and Factor 2 scores were highly correlated $(r=.85)$, making any inferences specific to one factor difficult. For these reasons, we only analyzed data based on total PCL-R score.

Mean age and years of formal education were 33, 28, and 27, and 9.3, 10.3, and 10.2, years for schizophrenic patients, psy- chopaths, and nonpsychopaths, respectively. The three groups did not differ significantly in age or education.

We paid each inmate volunteer $\$ 5.00$ for the PCL-R interview and $\$ 10.00$ for the experiment. The total of $\$ 15.00$ was equivalent to two days prison wage. As an additional incentive, we told the participants that the one who had the best reaction time and accuracy would receive an extra $\$ 10.00$.

\section{Physiologic Recording}

We recorded scalp potentials from tin electrodes (ElectroCap International, Eaton, $\mathrm{OH}$ ) placed over prefrontal (F7, Fpz, and F8), frontal (F3, Fz, and F4), temporal (T3 and T4), central (C3, $\mathrm{Cz}$, and $\mathrm{C} 4)$, and parietal (P3, Pz, and P4) sites according to the International 10-20 System of electrode placement. Eye movements were recorded from a channel placed beneath the right eye. All electrodes were referenced to an electrode located at the right mastoid process. One additional channel, left mastoid to right mastoid, was recorded for the purposes of allowing digital re-referencing to an average of left and right mastoids (Nunez 1981, 1990). Electrical impedance for each site was below 5 kOhms throughout the experiment.

The electroencephalogram (EEG) channels (Grass-Telefactor [Warwick, RI] Model 8-18C) were amplified with a bandpass of .1 to $70 \mathrm{~Hz}$, digitized on-line at a rate of 256 samples/sec, and recorded on computer hard disk. EEG was then digitally filtered with a zero-phase shift $30 \mathrm{~Hz}$ low pass filter to reduce electromyographic contamination. The sampling epoch was $900 \mathrm{msec}$, beginning with a $100 \mathrm{msec}$ prestimulus baseline period. Artifact rejection was performed before averaging to reject trials contaminated by blinks (greater than $100 \mu \mathrm{V}$ ) or excessive muscular activity. Two participants (one schizophrenic patient and one nonpsychopath) with excessive artifacts (more than 30\% of trials) were dropped from the analyses. For the remainder of the participants, these rejected epochs did not exceed $10 \%$ of the trials in any condition. There were no group differences in the number of trials averaged in any condition.

\section{Procedure}

The experiment was conducted in a small room in a secluded, quiet part of the institution. After attachment of the electrodes, the participant was seated in a comfortable chair approximately $60 \mathrm{~cm}$ from the computer monitor. The participant was instructed not to blink or move during each trial, except for using his index finger to press a marked key on a computer keyboard in response to Go stimuli. The hand used to make the response was counterbalanced across participants. Reaction time and accuracy were equally stressed. The stimuli were randomly presented and consisted of an arrow that pointed either up or down $(50 \mathrm{msec}$ duration; 750-1250 random interstimulus interval). Stimuli were centrally presented in a square box with a visual angle of $4^{\circ} \times$ $4^{\circ}$. The participant was told that instructions would appear on the screen indicating the stimulus (up or down arrow) to which he should respond during the subsequent block of trials. Two types of blocks, each containing 30 trials (50/50 probability of Go or No Go trials) were presented. One block required the participant to respond to the down arrow and to inhibit a response to the up 

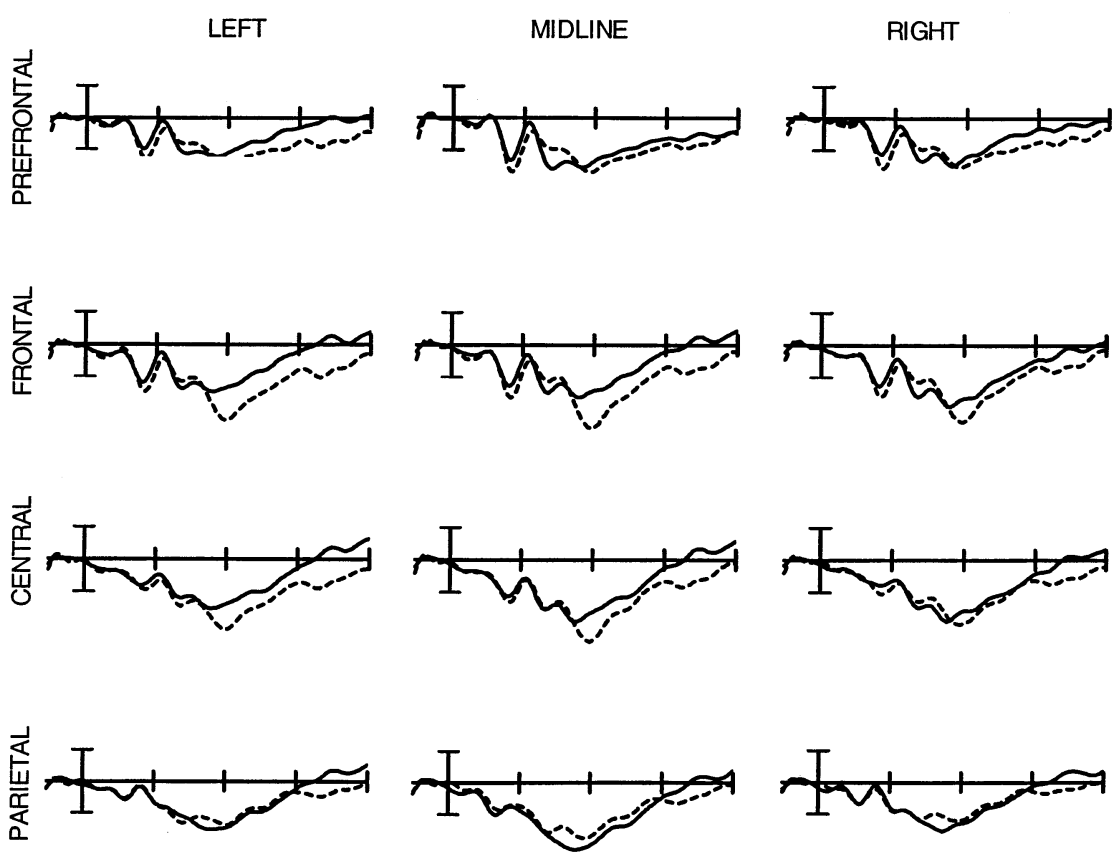

Figure 1. Grand mean event-related potentials for the Go and No Go stimuli for the schizophrenic patients.
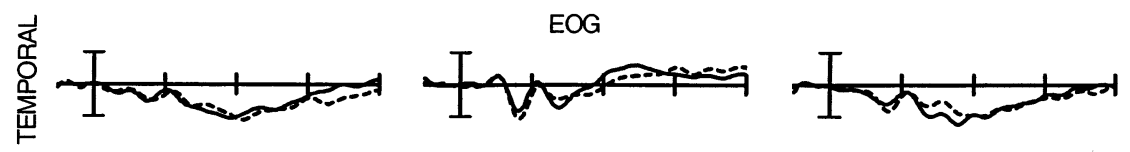

GO TRIALS

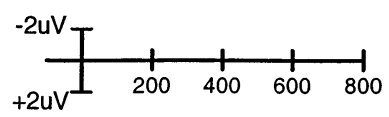

NO GO TRIALS

arrow (Block A); in the other block he was instructed to respond to the up arrow and to inhibit responses to the down arrow (Block B). Block A was presented 13 times and Block B was presented 5 times in the following order: AAABAAABAB, 5 min rest, AAABAAAB. This procedure was used in order to establish a dominant response tendency to the down arrows. Some investigators have found that establishing a dominant response and then having participants switch the learned response can elicit stronger response inhibition activation (Nativ et al 1992). Preliminary analyses indicated, however, that in this paradigm there was no effect of training on the behavioral or ERP data. Furthermore, the ERP signal-to-noise characteristics were poor for Block B stimuli and for these reasons we report only data from Block A. Prior to recording, the participant performed a block of 10 practice trials, repeated twice, to ensure that he understood the instructions.

\section{Analyses of Behavioral Data}

Reaction times, percentage of correct hits, and errors of commission were computed. Any response delayed by more than 1000 msec after stimulus onset was counted as an error. We used planned comparisons to compare the behavioral results across groups.

\section{ERP Data Reduction}

Separate analyses of variance (ANOVAs) were performed on the ERP data, one for lateral sites and one for midline sites. These analyses included factors of Group (schizophrenics, psychopath, nonpsychopaths), Condition (Go, No Go), and Site (prefrontal [F7, F8], frontal [F3, F4], temporal [T3, T4], central [C3, C4], and parietal [P3, P4] for lateral analyses; prefrontal [Fpz], frontal $[\mathrm{Fz}]$, central $[\mathrm{Cz}]$, and parietal $[\mathrm{Pz}]$ for midline analyses). For lateral sites, there also was a factor for Hemisphere (left, right). Two ERP components of interest were measured (relative to the $100 \mathrm{msec}$ prestimulus baseline) separately for the Go and No Go trials for each participant. These components were the N275 (225-325 msec window) and the P375 (325-425 msec window). The latency window used to quantify the mean amplitude of the N275 was centered on the peak latency of the No Go activity shown in the grand-average difference wave (No Go - Go trials) and from visual inspection of the ERP plots from similar studies (Nativ et al 1992; Schroger 1993). The N275 can best be 
Table 1. Behavioral Data for Schizophrenic Patients, Psychopaths, and Nonpsychopaths

\begin{tabular}{|c|c|c|c|c|c|c|}
\hline & \multicolumn{2}{|c|}{$\begin{array}{l}\text { Reaction times } \\
\quad(\mathrm{msec})\end{array}$} & \multicolumn{2}{|c|}{$\begin{array}{l}\text { Percentage of } \\
\text { correct hits }\end{array}$} & \multicolumn{2}{|c|}{$\begin{array}{l}\text { Errors of } \\
\text { commission }\end{array}$} \\
\hline & Mean & (SD) & Mean & (SD) & Mean & (SD) \\
\hline Schizophrenic patients & 407 & $(45.7)$ & 94.6 & (8.6) & 9.01 & $(5.8)$ \\
\hline Psychopaths & 381 & $(39.1)$ & 94.1 & (13.7) & 5.60 & (5.5) \\
\hline Nonpsychopaths & 404 & $(47.3)$ & 96.3 & $(7.0)$ & 4.26 & (3.1) \\
\hline
\end{tabular}

visualized in difference waves. The latency window used to quantify the mean amplitude of the P375 was centered on the peak latency of the P375 in the grand-average waveforms. Other effects of interest were tested using simple effects analyses or Tukey's multiple comparisons. The Geisser-Greenhouse correction was used for any repeated measures containing more than one degree of freedom in the numerator (Geisser and Greenhouse 1958). All probability levels are reported using epsilon-adjusted degrees of freedom. The McCarthy and Wood (1985) correction was performed on any significant interaction involving Site or Hemisphere and is reported only in cases in which the interaction became nonsignificant.

In addition to the omnibus ANOVAs, we also computed a No Go activity measurement. This measurement was computed by subtracting the No Go N275 from the Go N275 at anterior scalp sites. Two measurements were computed: one for lateral sites (F7, F8, F3, and F4) and one for midline sites (Fpz and Fz). Planned orthogonal contrasts were then performed on these measurements to assess our hypothesis that the psychopaths and schizophrenic patients would show less No Go activity than would the nonpsychopaths.

\section{Results}

\section{Behavioral Measures}

There were no group differences in reaction time or percentage of correct hits (all $p s>.50$ ). Analyses of the responses to No Go trials (commission errors) revealed that schizophrenic patients made more inappropriate responses than did nonpsychopaths $[t(33)=-2.5, p<$ .022]. There was also a tendency for schizophrenic patients to make more inappropriate responses than psychopaths $[t(33)=-1.67, p<.10]$. There were no significant differences in behavioral performance between psychopaths and nonpsychopaths (see Table 1).

\section{Event-Related Potentials}

Grand mean ERPs for the Go and No Go stimuli for the schizophrenics, psychopaths, and nonpsychopaths are presented separately in Figures 1, 2, and 3, respectively. The N275 is best visualized in the No Go - Go grand mean ERP differences waves, which are illustrated for the three groups in Figure 4.
N275

Analyses of the amplitude of the N275 at lateral sites yielded a significant Group $\times$ Condition interaction $[F(2,31)=3.30, p=.05]$ and a Group $\times$ Condition $\times$ Site trend $[F(8,124)=1.83, p<.08]$. Analyses of simple effects indicated that the nonpsychopaths $[F(1,31)=$ $15.56, p<.0005]$, but not the psychopaths $[F(1,31)=.80$, $p>.37]$ or the schizophrenic patients $[F(1,31)=1.16$, $p>.29$ ], had a larger N275 to No Go trials than to Go trials. Follow-up analyses of a significant Group $\times$ Hemisphere interaction $[F(2,31)=3.87, p<.04]$ indicated that the N275 was strongly left lateralized in the nonpsychopaths $(p<.05)$, but that this lateralization was reduced in schizophrenic patients $(p>.09)$ and absent in psychopaths $(p>.43)$.

Analyses of the N275 at midline sites revealed a significant Group $\times$ Condition $\times$ Site interaction $[F(6,93)=2.79, p<.04, \epsilon=.65]$. The $\mathrm{N} 275$ was larger at anterior sites for No Go than for Go stimuli for the nonpsychopaths $[F(1,31)=17.99, p<.0002]$ and the schizophrenic patients $[F(1,31)=6.77, p<.02]$, but not for the psychopaths $[F(1,31)=2.36, p>.13]$.

As predicted, the No Go activity measurement analyses revealed that psychopaths showed reduced No Go activity compared to nonpsychopaths [lateral, $t(33)=2.58, p<$ .02 ; midline, $t(33)=2.16, p<.04]$. The comparison of the No Go activity measurement for the schizophrenic patients versus the nonpsychopaths revealed only a statistical trend at lateral sites $[t(33)=1.88, p<.07$; midline, $t(33)=1.27, p>.22]$.

Across all participants, the N275 was larger on No Go than on Go trials [main effect of Condition: lateral, $F(1,31)=12.36, p<.001$; midline, $F(1,31)=10.98, p<$ .003]. This effect was most pronounced in left anterior regions [Condition $\times$ Site interaction: lateral, $F(4,124)=$ 18.27, $p<.001, \epsilon=.55$; midline, $F(3,93)=7.96, p<$ $.002, \epsilon=.65$; Condition $\times$ Hemisphere interaction, $F(1,31)=7.29, p<.01]$.

\section{P375}

Significant Group $\times$ Condition [lateral, $F(2,31)=9.02$, $p<.002$; midline, $F(2,31)=10.30, p<.0004]$ and Group $\times$ Condition $\times$ Site interactions [lateral, $F(8,124)=3.47, p<.009, \epsilon=.59$; midline, $F(6,93)=$ 3.04, $p<.022, \epsilon=.72]$ were found for amplitude of the P375 at lateral and midline sites. This pattern of effects indicated three things. First, as expected, the P375 in nonpsychopaths was larger on Go than on No Go trials, with the effect being larger at parietal sites than at prefrontal or temporal sites. Second, schizophrenic patients showed no P375 differentiation between Go and No Go trials, probably a reflection of their small P375 on the 

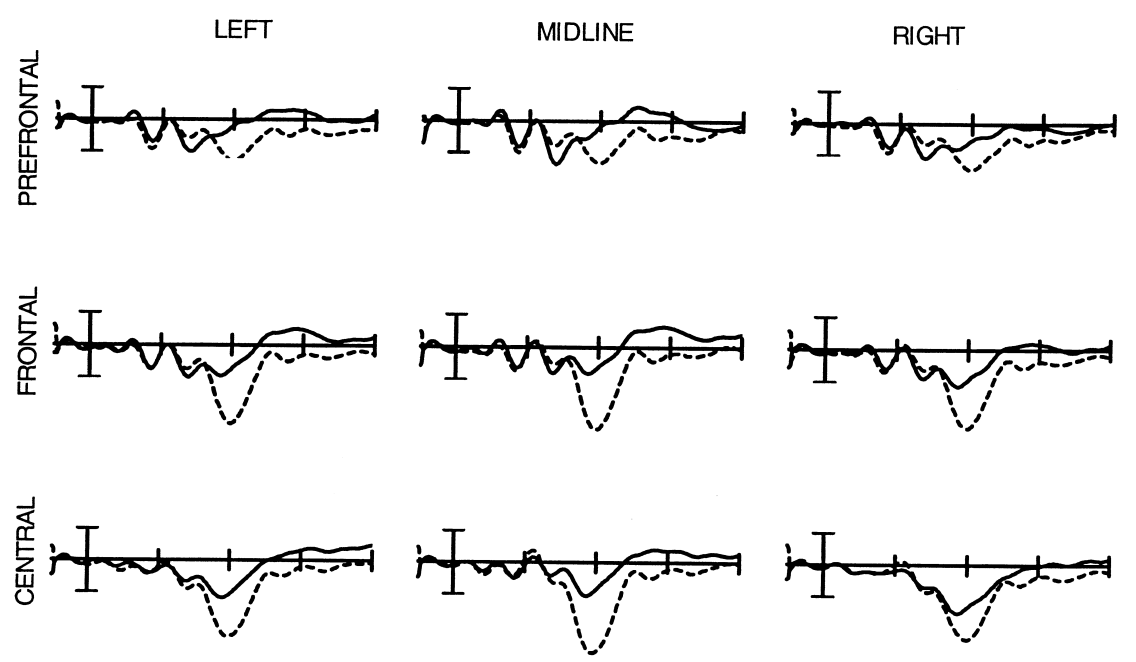

Figure 2. Grand mean event-related potentials for the Go and No Go stimuli
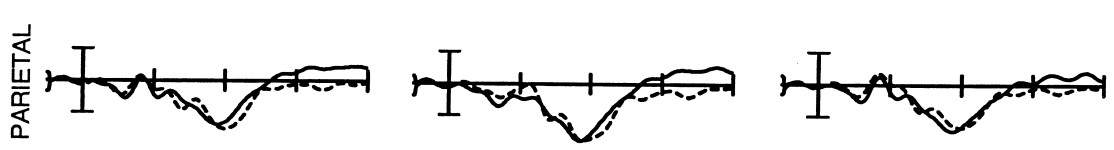
for the psychopaths.
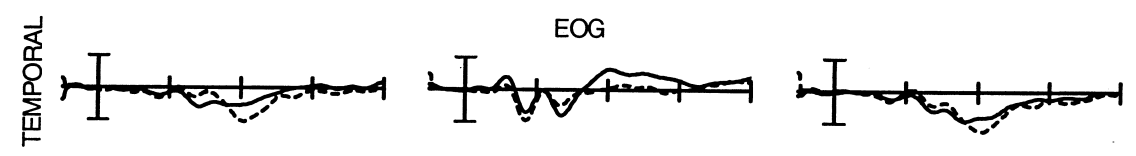

GO TRIALS

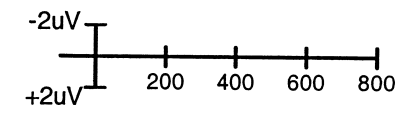

\section{NO GO TRIALS}

Go trials (there were no significant group differences in the amplitude of the P375 on the No Go trials). Finally, in the psychopaths, the P375 on the Go trials was very small at anterior and central sites. Indeed, their P375 at these sites was significantly smaller on Go trials than on No Go trials, whereas the opposite was true of the nonpsychopaths.

There was also a significant Group $\times$ Hemisphere interaction $[F(2,31)=4.11, p<.03]$ for the $\mathrm{P} 375$ amplitude. This effect indicated that the P375 was strongly right lateralized in nonpsychopaths $[F(1,31)=18.13, p<$ .0002], slightly less lateralized in psychopaths $[F(1,31)=$ $4.71, p<.04]$, and was not significantly lateralized in schizophrenic patients $[F(1,31)=0.10, p=.74]$.

Across all participants, the P375 was larger at parietal sites on Go trials than on No Go trials. The P375 on No Go trials was largest at central sites [Condition $\times$ Site interaction: lateral, $F(4,124)=12.55, p<.00001, \epsilon=$ .59 ; midline, $F(6,93)=25.83, p<.00001, \epsilon=.72]$.
These effects were more pronounced at right hemisphere sites than at left hemisphere sites [Condition $\times$ Hemisphere interaction, $F(1,31)=5.42, p<.03$; Condition $\times$ Site $\times$ Hemisphere interaction, $F(4,124)=3.81, p<$ $.010, \epsilon=.82]$.

\section{Discussion}

This study was designed to investigate the behavioral and neural components of response selection in schizophrenic patients and in psychopaths. The results generally supported our hypotheses that, compared to other individuals, schizophrenic patients would show impaired behavioral performance (more errors of commission) and reduced electrocortical activation during trials that required response inhibition. The results of the behavioral analyses indicated that schizophrenic patients made significantly more errors of commission than did the nonpsychopaths, and there was a statistical trend for the schizophrenic 

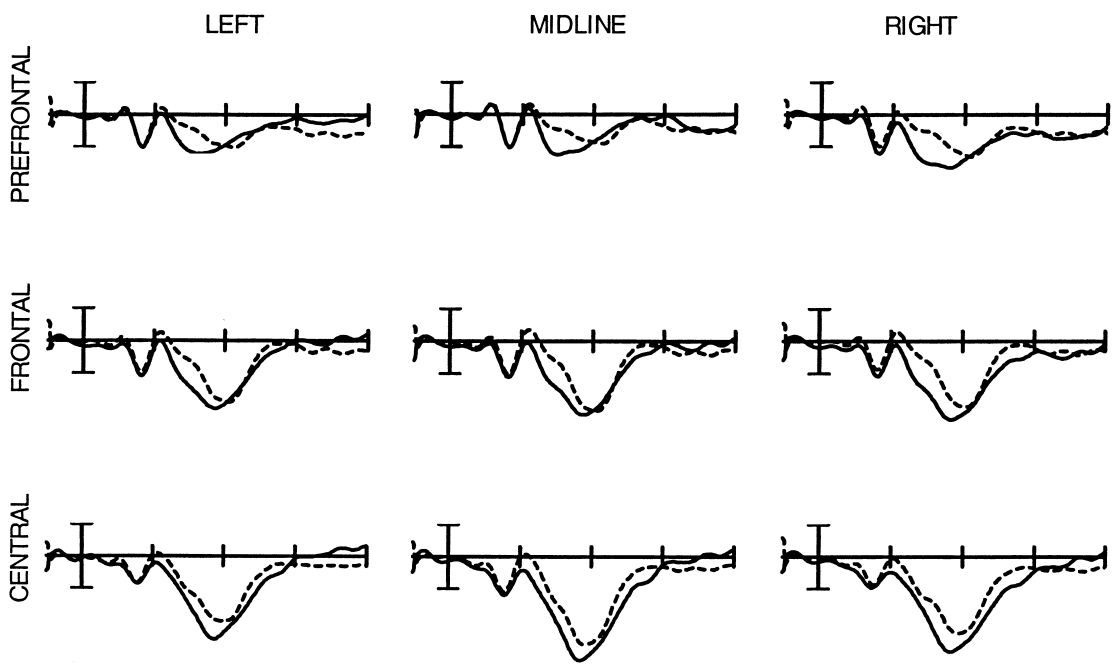

Figure 3. Grand mean event-related potentials for the Go and No Go stimuli for the nonpsychopaths.
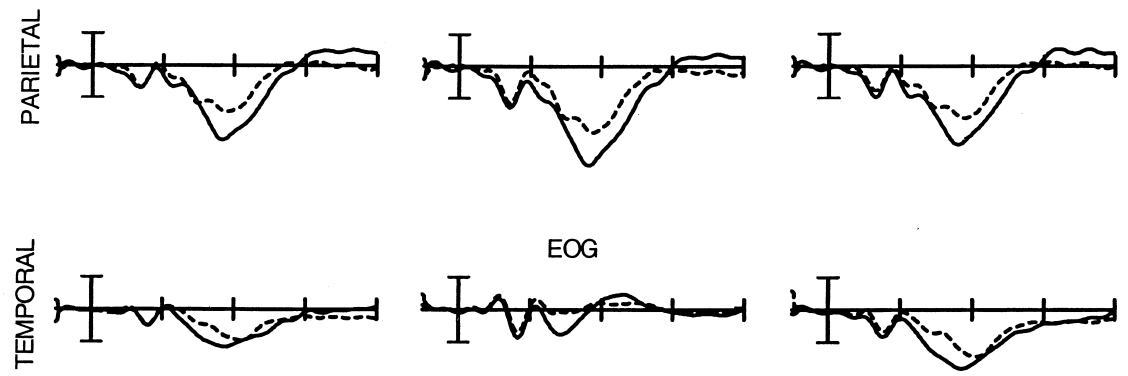

GO TRIALS

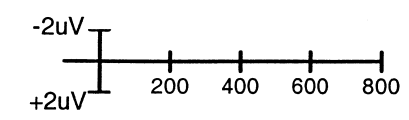

NO GO TRIALS

patients to make more errors of commission than psychopaths. These findings are consistent with previous findings of excessive errors of commission in tasks that demand response inhibition in schizophrenia (Frith et al 1991).

The results of the ERP data analyses indicated that the nonpsychopaths showed the expected greater frontal negativity (N275) for the No Go stimuli than for the Go stimuli. This effect was attenuated in the schizophrenic patients and absent in the psychopaths. The question of whether or not the N275 component reflects the neural activity directly involved in response inhibition remains controversial. On the one hand, Kopp et al (1996) reported that priming, so as to enhance the strength of the impulse to respond to the No Go stimuli, enhanced that magnitude of this frontal negative component (see also Nativ et al 1992). On the other hand, Kok (1986) reported that increasing the difficulty in discriminating between Go and No Go stimuli by degrading the clarity of the stimuli reduced the amplitude of this component. This observation is consistent with the hypothesis that the frontal negative component might reflect the greater attention required to inhibit rather than to execute responses (Kopp et al 1996; Schroger 1993). When the difficulty of discriminating between stimuli is increased, the difference in attentional demands between No Go and Go trials would be relatively less.

In our study, in which the frequency of No Go trials was equal to that of Go trials, there is less reason to propose that the No Go trials required greater attention to the stimulus, than might have been the case in the study of Kopp et al (1996), in which No Go events were relatively infrequent. Therefore, there is less reason to propose that attentional demands account for the N275 component observed in our study.

However, if the N275 component reflects, at least in part, the attentional demands of the No Go trials, the reduced amplitude of this component in schizophrenia and psychopathy might be attributed to attentional impairment in the two conditions. There is a large body of evidence demonstrating attentional abnormalities in schizophrenia 

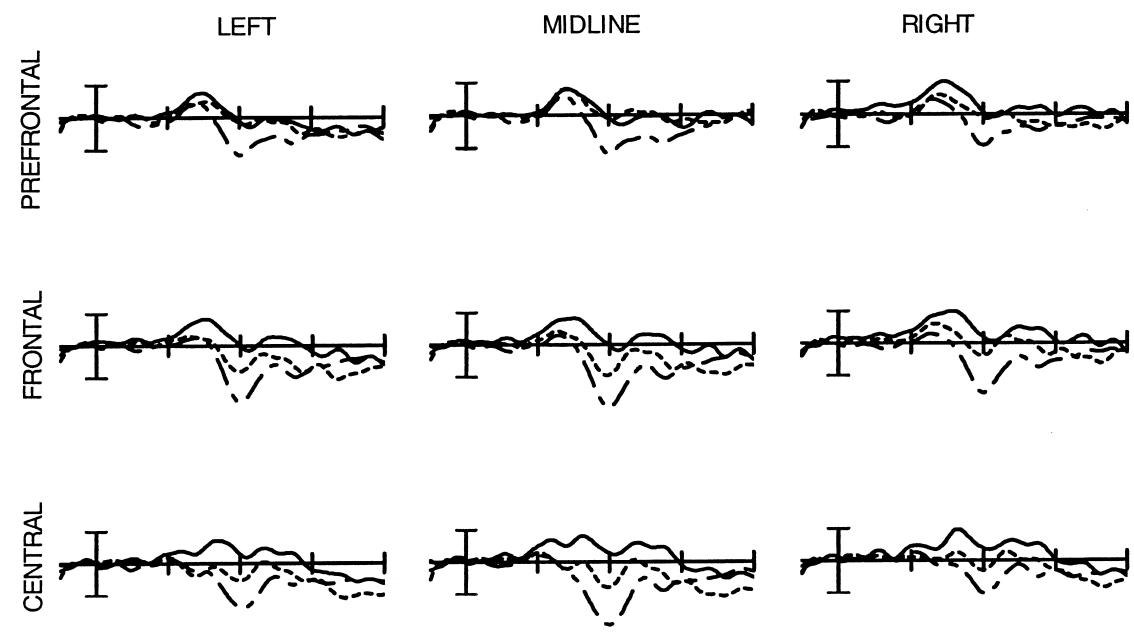

Figure 4. Grand mean event-related potential No Go-Go difference waves for schizophrenic, psychopath, and nonpsy-
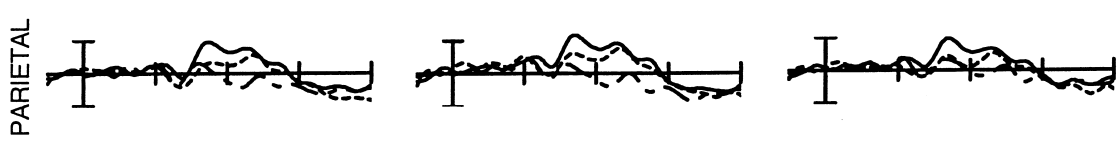
chopath patients.
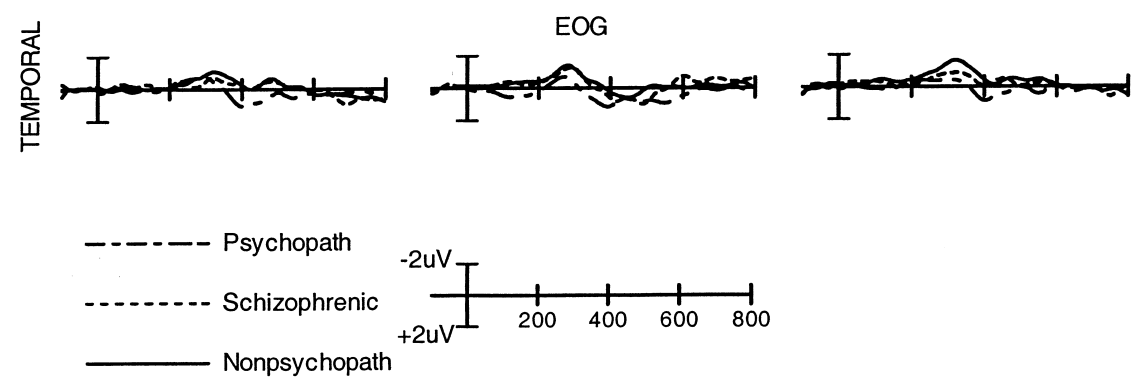

(recently reviewed by Green 1998) and a growing literature in support of such impairments in psychopathy (Kiehl et al 1999a, 1999b; Kosson and Harpur 1997). Interestingly, Lapierre and colleagues found that psychopaths performed more poorly (errors of commission) than did nonpsychopaths during a Go/No Go task that employed a strong spatial attention manipulation (Lapierre et al 1995). This suggests that strong attention manipulations may aid in elucidating the nature of the cognitive deficits in psychopaths.

Although the generators of the N275 have not been precisely localized, evidence from neuroimaging studies suggests that the anterior cingulate, lateral frontal cortex, and left superior frontal cortex may be involved in response inhibition (Carter et al 1998; Kiehl et al 2000; Konishi et al 1999). There is a rather large body of evidence demonstrating that the anterior cingulate and lateral frontal cortex are abnormal in schizophrenia (Liddle et al 1992; Yuasa et al 1995) and growing evidence of such abnormalities in psychopathy (Kiehl et al 1999b). Given that response inhibition is most probably a function of a complex neural circuit located in a spatially distributed network, it may be possible that the topographic ERP differences observed between the patient groups may reflect abnormalities at one or more cerebral sites. Although the circuits involved in response inhibition have yet to be delineated in full, it is likely that the fronto-striato-thalamo-cortical loops that provide feedback to frontal cortex, play a role in regulating response inhibition processes. In particular, lesions affecting the loops that provide feedback to dorsolateral prefrontal cortex and to anterior cingulate cortex have both been implicated in defects in response inhibition (Chow and Cummings 1999). What is clear from the present results is that these abnormalities occur early in processing, beginning around $200 \mathrm{msec}$ poststimulus.

In addition to group differences in the amplitude of $\mathrm{N} 275$, the groups also differed in the hemispheric asym- 
metry of this component. In the nonpsychopathic control participants, the N275 was left lateralized, whereas this effect was reduced in the patient groups. To our knowledge, hemispheric asymmetries of the No Go N275 have not been investigated. Previous studies have shown that both schizophrenia (Crow 1997) and psychopathy (e.g., Hare and McPherson 1984) are characterized by reduced cerebral asymmetries.

Psychopaths and schizophrenic patients also differed from control participants in the amplitude of the P375 to Go stimuli. Although reduced P3s are often found to auditory target stimuli in schizophrenic patients, the evidence for reduced P3 amplitude in response to visual oddball stimuli is less consistent (Kochi et al 1996; Shelley et al 1996; Wagner et al 1989). We have previously reported that the P3 to visual oddball stimuli is reduced in psychopaths relative to nonpsychopaths (Kiehl et al 1999b); however, most of these studies employed "oddball" paradigms, in which the salience of the target stimuli is very different from the Go stimuli in this experiment. The P375 to Go stimuli is usually interpreted as a reflection of processes related to response selection and decision making. As with the N275, the patient groups showed reduced hemispheric asymmetries for the P375, suggesting that both conditions can be characterized by reduced cerebral asymmetry. These findings suggest that both schizophrenic patients and psychopaths differ from nonpsychopaths in the neural ensembles that generate this component.

It should be noted that the population of incarcerated schizophrenic patients participating in the present study may not be characteristic of the larger population schizophrenic patients. For the purpose of this study, however, we considered that it was preferable to compare incarcerated psychopaths with incarcerated schizophrenic patients and with incarcerated nonpsychotic nonpsychopaths to minimize differences attributable to incarceration. It should also be noted that the schizophrenic patients were on atypical neuroleptics, which raises the issues that some of the behavioral and ERP differences between the schizophrenic patients and others may be due to the effects of medication.

In conclusion, we have demonstrated that abnormalities of cerebral activity during a Go/No Go task in incarcerated schizophrenic patients and incarcerated psychopaths are similar, though apparently not identical. In particular, the schizophrenic patients tended to show greater deficits in performance, whereas the psychopaths showed more marked reduction in the frontal N275 ERP component. These findings provide further support for the hypothesis that similar, but perhaps not identical, neural circuits play a role in the disorders of behavioral inhibition that occur in the two conditions.
This research was supported in part by grants from the Medical Research Council (MRC) of Canada, the British Columbia Health Services, and British Columbia Medical Services Foundation, John Wacker Foundation, and funds from the Schizophrenia Division, Department of Psychiatry, University of British Columbia. The first author was supported by the Michael Smith Graduate Scholarship, Medical Research Council of Canada. The second author was supported by a Killam Graduate Scholarship.

The authors thank the staff and inmates of the Regional Health Center (Pacific), a division of Correctional Services of Canada, for their assistance and cooperation. We also would like to thank Sara Johnston, Derek Mitchell, Erin Fennell, and Hugues Herve for their assistance with PCL-R assessments.

\section{References}

American Psychiatric Association (1994): Diagnostic and Statistical Manual of Mental Disorders, 4th ed. Washington, DC: American Psychiatric Association.

Andreasen NC (1979): Thought, language, and communication disorders: I. Clinical assessment, definition of terms, and evaluation of their reliability. Arch Gen Psychiatry 36:13151321.

Andreasen NC, Amdt S, Alliger R, Miller D (1995): Symptoms of schizophrenia: Methods, meanings, and mechanisms. Arch Gen Psychiatry 52:341-351.

Annett M (1970): Classification of hand preference by association analysis. Br J Psychol 61:303-321.

Baxter R, Liddle PF (1998): Neuropsychological deficits associated with schizophrenic syndromes. Schizophr Res 30:239249.

Bilder RM, Mukherjee S, Rieder RO, Pandurangi AK (1985): Symptomatic and neuropsychological components of defect states. Schizophr Bull 3:409-419.

Bleuler E (1950): Dementia Praecox or the Group of Schizophrenias [Zinkin $\mathrm{J}$, translator]. New York: International Universities Press [original work published 1950].

Blumer D, Benson DF (1975): Personality changes with frontal lobe lesions. In: Benson DF, Blumer D, editors. Psychiatric Aspects of Neurological Disease. New York: Grune \& Stratton, 151-170.

Brown D, Fenwick P, Howard R (1989): The contingent negative variation in a Go/No Go avoidance task: Relationships with personality and subjective state. Int J Psychophysiol 7:35-45.

Carter CS, Braver TS, Barch DM, Botvinick MM, Noll D, Cohen JD (1998): Anterior cingulate cortex, error detection, and the online monitoring of performance. Science 280:747-749.

Chow TW, Cummings JL (1999): Frontal-subcortical circuits. In: Miller BL, Cummings JL, editors. The Human Frontal Lobes: Functions and Disorders. New York: Guilford, 3-26.

Cleckley H (1976): The Mask of Sanity, 5th ed. St. Louis: Mosby.

Crow TJ (1997): Schizophrenia as failure of hemispheric dominance for language. Trends Neurosci 20:339-343.

Damasio AR, Tranel D, Damasio H (1990): Individuals with sociopathic behavior caused by frontal damage fail to respond to autonomically to social stimuli. Behav Brain Res 41:81-94.

Ebmeier KP, Blackwood DH, Murray C, Souza V, Walker M, Dougall N, et al (1993): Single-photon emission computed 
tomography with $99 \mathrm{~m}$ Tc-exametazime in unmedicated schizophrenic patients. Biol Psychiatry 33:487-495.

Eimer M (1993): Effects of attention and stimulus probability on ERPs in a go/no-go task. Biol Psychol 35:123-138.

Frith CD, Leary J, Cahill C, Johnstone EC (1991): Disabilities and circumstances of schizophrenic patients-a follow-up study. IV. Performance on psychological tests. $\mathrm{Br} J$ Psychiatry 19(suppl 13):26-29.

Fulero S (1996): Review of the Hare-Psychopathy ChecklistRevised. In: Conoley JC, Impara JC, editors. 12th Mental Measurements Yearbook. Lincoln, NE: Buros Institute, 453454.

Geisser S, Greenhouse SW (1958): An extension of Box's results on the use of the F distribution in multivariate analysis. Ann Math Stat 29:885-891.

Gemba H, Sasaki K (1989): Potential related to no-go reaction of go/no-go hand movement task with color discrimination in human. Neurosci Lett 101:263-268.

Gillstrom B (1995): Abstract thinking in criminal psychopaths. Unpublished doctoral thesis, University of British Columbia, Vancouver.

Gorenstein EE (1982): Frontal lobe functions in psychopaths. $J$ Abnorm Psychol 91:368-379.

Gorham DR (1956): A proverbs test for clinical and experimental use. Psychol Rep 2:1-12.

Green MF (1998): Schizophrenia from a Neurocognitive Perspective. Boston: Allyn and Bacon.

Hare RD (1984): Performance of psychopaths on cognitive tasks related to frontal lobe functions. J Abnorm Psychol 93:133140.

Hare RD (1991): The Hare Psychopathy Checklist-Revised. Toronto: Multi-Health Systems.

Hare RD (1993): Without Conscience: The Disturbing World of the Psychopaths Among Us. New York: Pocket Books.

Hare RD, McPherson LM (1984): Psychopathy and perceptual asymmetry during verbal dichotic listening. J Abnorm Psychol 93:140-149.

Harpur TJ, Hare RD, Hakstian R (1989): A two-factor conceptualization of psychopathy: Construct validity and implications for assessment. Psychol Assess J Consult Clin Psychol $1: 6-17$.

Hart SD, Forth AE, Hare RD (1990): Neuropsychological assessment of criminal psychopaths. J Abnorm Psychol 99: 374-379.

Hillyard SA, Courchesne E, Krausz HI, Picton TW (1976): Scalp topography of the P3 wave in different auditory decision tasks. In: McCallum WC, Knott JR, editors. The Responsive Brain. Bristol, UK: John Wright, 81-87.

Jodo E, Inoue J (1990): Effects of practice on the P300 in a Go/NoGo task. Electroencephalogr Clin Neurophysiol 76: 249-257.

Jodo E, Kayam Y (1992): Relation of a negative ERP component to response inhibition in a Go/No-go task. Electroencephalogr Clin Neurophysiol 82:477-482.

Karlin L, Martz MJ, Mordkoff AM (1969): Motor performance and sensory-evoked potentials. Electroencephalogr Clin Neurophysiol 28:307-313.

Kiehl KA, Hare RD, Liddle PF, McDonald JJ (1999a): Reduced
P300 responses in criminal psychopaths during a visual oddball task. Biol Psychiatry 45:1498-1507.

Kiehl KA, Hare RD, McDonald JJ, Brink J (1999b): Semantic and affective processing in psychopaths: An event-related potential study. Psychophysiology 36:765-774.

Kiehl KA, Liddle PF, Hopfinger JB (2000): Error processing and the rostral anterior cingulate: An event-related fMRI study. Psychophysiology 37:216-223.

Kochi K, Koenig T, Strik WK, Lehmann D (1996): Event-related potential P300 microstate topography during visual one- and two-dimensional tasks in chronic schizophrenics. Eur Arch Psychiatry Clin Neurosci 246:288-296.

Kok A (1986): Effects of degradation of visual stimuli on components of the event-related potentials (ERP) in Go/Nogo reaction tasks. Biol Psychol 23:21-38.

Konishi S, Nakajima K, Uchida I, Kikyo H, Kameyama M, Miyashita Y (1999): Common inhibitory mechanism in human inferior prefrontal cortex revealed by event-related functional MRI. Brain 122:981-991.

Kopp B, Mattler U, Goertz R, Rist F (1996): N2, P3 and the lateralized readiness potential in a nogo task involving selective response priming. Electroencephalogr Clin Neurophysiol 99:19-27.

Kosson DS, Harpur TJ (1997): Attentional functioning of psychopathic individuals: Current evidence and developmental implications. In: Burack JA, Enns JT, editors. Attention, Development, and Psychopathology. New York: Guilford, 379-402.

Kraepelin E (1919): Demetia Praecox and Paraphrenia [Barclay RM, translator]. Chicago: Chicago Medical Books.

Lapierre D, Braun CMJ, Hodgins S (1995): Ventral frontal deficits in psychopathy: Neuropsychological test findings. Neuropsychologia 11:139-151.

Liddle PF (1987a): Schizophrenic syndromes, cognitive performance and neurological dysfunction. Psychol Med 17:49-58.

Liddle PF (1987b): The symptoms of chronic schizophrenia: A re-examination of the positive-negative dichotomy. $\mathrm{Br} J$ Psychiatry 151:145-151.

Liddle PF, Barnes TRE (1990): Syndromes of chronic schizophrenia. Br J Psychiatry 157:558-561.

Liddle PF, Friston KJ, Frith CD, Hirsch SR, Jones T, Frackowiak RSJ (1992): Patterns of cerebral blood flow in schizophrenia. Br J Psychiatry 160:179-186.

Liddle PF, Morris DL (1991): Schizophrenia syndromes and frontal lobe performance. Br J Psychiatry 158:340-345.

Malla AK, Norman RM, Williamson P, Cortese L (1993): Three syndrome concept of schizophrenia: A factor analytic study. Schizophr Res 10:143-150.

McCarley RW, Shenton ME, O'Donnell BF, Nestor PG (1993): Uniting Kraeplin and Bleuler: The psychology of schizophrenia and the biology of temporal lobe abnormalities. Harv Rev Psychiatry 1:36-56.

McCarthy G, Wood CC (1985): Scalp distributions of eventrelated potentials: An ambiguity associated with analysis of variance models. Electroencephalogr Clin Neurophysiol 62: 203-208.

Naito E, Matsumura M (1994): Movement-related potentials associated with motor inhibition as determined by use of a stop signal paradigm in humans. Cogn Brain Res 2:139-146. 
Nativ A, Lazarus JC, Nativ J, Joseph J (1992): Potentials associated with the initiation and inhibition of visually triggered finger movement in humans: The "no-go potential" in the go/no-go paradigm. Int J Neurosci 66:107-118.

Newman JP (1998): Psychopathic behavior: An information processing perspective. In: Cooke DJ, Forth AE, Hare RD, editors. Psychopathy: Theory, Research, and Implications for Society. Dordrecht, The Netherlands: Kluwer, 81-104.

Newman JP, Kosson DS (1986): Passive avoidance learning in psychopathic and nonpsychopathic offenders. J Abnorm Psychol 95:252-256.

Newman JP, Patterson CM, Howland EW, Nichols SL (1990): Passive avoidance in psychopaths: The effects of reward. Pers Individual Differences 11:1101-1114.

Newman JP, Wallace JF (1993): Psychopathy and cognition. In: Kendall PC, Dobson KS, editors. Psychopathology and Cognition. New York: Academic Press, 293-349.

Newman JP, Widom CS, Nathan S (1985): Passive avoidance in syndromes of disinhibition: Psychopathy and extraversion. $J$ Pers Soc Psychol 48:1316-1327.

Nunez PL (1981): Electric Fields of the Brain. New York: Oxford University Press.

Nunez PL (1990): Physical principles and neurophysiological mechanisms underlying event-related potentials. In: Rohrbaugh JW, Parasuraman R, Johnson R Jr, editors. EventRelated Brain Potentials. New York: Oxford University Press, 19-36.

Pardo JV, Pardo PJ, Janer KW, Raichle ME (1990): The anterior cingulate cortex mediates processing selection in the Stroop attentional conflict paradigm. Proc Natl Acad Sci USA $87: 256-259$.

Patterson CM, Newman JP (1993): Reflectivity and learning from aversive events: Toward a psychological mechanism for the syndromes of disinhibition. Psychol Rev 100:716-736.

Pfefferbaum A, Ford JM (1988): ERPs to stimuli requiring response production and inhibition; effects of age, probability and visual noise. Electroencephalogr Clin Neurophysiol 71: 55-63.
Pfefferbaum A, Ford JM, Weller BJ, Kopell BS (1985): ERPs to reponse production and inhibition. Electroencephalogr Clin Neurophysiol 60:423-434.

Raine A (1985): A psychometric assessment of Hare's checklist for psychopathy on an English prison population. $\mathrm{Br} J$ Clin Psychol 24:247-258.

Raz S, Raz N (1990): Structural brain abnormalities in the major psychoses: A quantitative review of the evidence from computerized imaging. Psychol Bull 108:93-108.

Schroger E (1993): Event-related potentials to auditory stimuli following transient shifts of spatial attention in a Go/No go task. Biol Psychol 36:183-207.

Shelley A, Grochowski S, Lieberman JA, Javitt DC (1996): Premature disinhibition of P3 generation in schizophrenia. Biol Psychiatry 39:714-719.

Simson R, Vaughan HG Jr, Ritter W (1977): The scalp topography of potentials in auditory and visual Go/No-Go tasks. Electroencephalogr Clin Neurophysiol 43:864-875.

Wagner M, Kurtz G, Engel RR (1989): Normal P300 in acute schizophrenics during a continuous performance test. Biol Psychiatry 25:792-795.

Waid WT, Orne MT (1982): Reduced electrodermal response to conflict, failure to inhibit dominant behaviors, and delinquency proneness. J Pers Soc Psychol 43:769-774.

Ward PB, Catts SV, McConaghy N (1992): P300 and conceptual loosening in normals: An event-related potential correlate of “thought disorder?" Biol Psychiatry 31:650-660.

Watanabe M (1986): Prefrontal unit activity during delayed conditional Go/No Go discrimination in the monkey. II. Relation to go and no-go responses. Brain Res 382:15-27.

Williamson SE (1991): Cohesion and coherence in the speech of psychopathic criminals. Unpublished doctoral dissertation, University of British Columbia, Vancouver.

Yuasa S, Kurachi M, Suzuki M, Kadono Y, Matsui M, Saitoh O, et al (1995): Clinical symptoms and regional cerebral blood flow in schizophrenia. Eur Arch Psychiatry Clin Neurosci 246:7-12. 